\title{
Visual outcomes after vitrectomy for epiretinal membrane in pseudophakic eyes with a diffractive trifocal intraocular lens.
}

Luis Arrevola-Velasco ( $\square$ larrevola@telefonica.net)

Clinica Baviera Valencia https://orcid.org/0000-0003-3828-8524

Jaime Beltrán

Clinica Baviera Valencia

Maria Jesus Gimeno

Clinica Baviera Valencia

Julio Ortega-Usobiaga

Clinica Baviera Valencia

Vasyl Druchkiv

Clinica Baviera Valencia

Fernando Llovet-Osuna

Clinica Baviera Valencia

Julio Baviera-Sabater

Clinica Baviera Valencia

\section{Research Article}

Keywords: diffractive multifocal intraocular lens, trifocal intraocular lens, epiretinal membrane, vitrectomy, pseudophakic eyes.

Posted Date: April 27th, 2021

DOl: https://doi.org/10.21203/rs.3.rs-364268/v1

License: (c) (i) This work is licensed under a Creative Commons Attribution 4.0 International License.

Read Full License 


\section{Abstract}

Purpose: To evaluate the effect on visual outcomes of a diffractive trifocal intraocular lens (IOL) in pars plana vitrectomy (PPV) for removal of epiretinal membrane (ERM) in pseudophakic eyes.

Methods: This is retrospective case-series study on 20 eyes with a single model of trifocal IOL that underwent PPV for removal of ERM between January 2015 and September 2018 in our clinics. Follow up was at least 1 year. Primary outcome measure was mean change in visual acuity. Other outcome measures were mean change in central macular thickness (CMT), recovery of the external retinal layers, and change in spherical equivalent (SE).

Results: Mean corrected distance visual acuity (CDVA) was $0.03 \pm 0.03 \log M A R$ after phacoemulsification; this worsened to $0.23 \pm 0.10 \log M A R$ with ERM, improving to $0.10 \pm 0.04 \log$ MAR 12 months after PPV $(p=0.001)$. Mean uncorrected near visual acuity (UNVA) was Jaeger $2.62 \pm 0.51$ after lensectomy. This worsened to Jaeger $5.46 \pm 1.67$ with ERM and improved to the initial Jaeger $2.69 \pm 0.84$ after PPV $(p=0.005)$. CMT decreased significantly, from $380.15 \pm 60.50 \mu \mathrm{m}$ with the ERM to $313.70 \pm 36.98 \mu \mathrm{m}$ after PPV. Mean SE after lensectomy was $-0.18 \pm 0.38 \mathrm{D}$, which minimally changed to $-0.18 \pm 0.47 \mathrm{D}$ after PPV $(p=0.99)$. The only complication recorded after PPV was a case of cystoid macular edema. No difficulties in visualization due to IOL design were reported during PPV.

Conclusion: PPV for ERM in eyes with this trifocal IOL is safe and effective, and allows recovery of the loss of UNVA.

\section{Key Messages}

It was known that PPV for ERM based on 23G and 25G techniques in pseudophakic eyes is a safe and effective procedure; anatomical factors such as ellipsoid zone disruption and the CDVA levels at the time of surgery are significantly relevant for visual outcomes.

Visual outcomes of PPV for ERM in eyes with this trifocal IOL are satisfactory in terms of UDVA and CDVA, and loss of UNVA is regained.

This model of diffractive trifocal IOL does not impair normal visualization during the PPV, and the PPV does not seem to affect centration and positioning of the $\mathrm{IOL}$, with no relevant refractive shift after the procedure.

\section{Introduction}

Epiretinal membrane (ERM) is a pathological proliferation of fibrotic and glial tissue over the internal limiting membrane (ILM) of the macula. It can be idiopathic or secondary to retinal conditions such as trauma, retinal detachment, and vascular or inflammatory diseases [1]. The prevalence of ERM increases from $<1 \%$ in patients aged under 50 years to $15 \%-28.1 \%$ in patients aged over 65 years, with no differences between genders [2]. ERM is more frequent after posterior vitreous detachment [2,3] and may 
produce visual impairment and metamorphopsia. The only treatment options are pars plana vitrectomy (PPV) and ERM peeling, which were first described by Machemer in 1978 [4]. Good visual and anatomical results have been reported since the introduction of the $23 \mathrm{G}$ and $25 \mathrm{G}$ microincision technique [5]. The most important factors for visual prognosis are those related to distortion of the retinal layers, especially the outer segments, central macular thickness (CMT) and inner retinal layer thickness, as determined by spectral domain optical coherence tomography (SD-OCT) [6, 7].

According to Eurostat, more than 4.3 million lensectomies were performed in the European Union in 2018, and a multifocal intraocular lens (IOL) was implanted in $5-10 \%$ of them depending on the country [8]. The procedure performed involved both cataract surgeries and refractive surgeries in clear lenses, both of which have proven very successful, even after long-term follow-up. Consequently multifocal IOLs are being implanted in younger patients [9]. A reduction in contrast sensitivity has been reported with diffractive trifocal IOLs [10] and many authors therefore recommend avoiding implantation of a multifocal IOL in patients with macular impairments such as ERM $[11,12]$. However others have reported good visual outcomes with implantation of multifocal IOL in patients with age-related macular degeneration and diabetic retinopathy [12]. One population-based prevalence study on 4439 subjects with an age $\geq 40$ years has shown a 10-year incidence of ERM of 8.4\% [13]. The cumulative incidence of ERM after cataract surgery has been reported to be $12 \%-17 \%$ depending on the series and the time lapse studied $[14,15]$.

The purpose of this study was to analyze and compare the visual and also the anatomical outcomes of PPV for ERM of a single diffractive trifocal IOL.

\section{Methods}

We performed an institutional retrospective case series study of patients from 5 centers of Clinica Baviera in Spain. The study was approved by the Institutional Review Board and the Research and Development Department before recruitment was initiated and followed the stipulations of the declaration of Helsinki. All the patients signed an informed consent document for their data to be retrieved from their clinical history. The data recorded included uncorrected distance visual acuity (UDVA), corrected distance visual acuity (CDVA), uncorrected near visual acuity (UNVA), refraction, intraocular pressure, refractive adjustment after lens surgery (bioptics), dye used for ERM and ILM removal, CMT and state of the retinal layers, especially the ellipsoid zone (photoreceptor inner/outer segments [IS/OS]) which was analyzed using spectral domain optical coherence tomography (SD-OCT). We also recorded argon laser photocoagulation data prior to PPV, Nd-YAG laser capsulotomy data, and surgical and postoperative complications. Clinical data were recorded at 3 timepoints in the clinical history: 3 months after lensectomy, prior to PPV and 12 months after PPV. The 3 SD-OCT platforms used were OCT 2000 (Topcon, Tokyo, Japan), Cirrus HD-OCT (Zeiss, Oberkochen, Germany), and Spectralis (Heidleberg Engineering, Heidelberg, Germany). The lensectomies were performed by 7 experienced cataract surgeons, who recorded no complications during or after the procedure, and the IOL implanted in all cases was the Finevision MicroF® (PhysIOL, Liege, Belgium). 
The PPVs were performed by 5 very experienced retinal surgeons using a Constellation Vision System platform (Alcon, Fort Worth Texas, USA). The dyes used for removal were Membrane Blue Dual (DORC, Zuidland, The Netherlands), Brilliant Blue (ILM-Blue, DORC, Zuidland, The Netherlands) and Trypan Blue (Membrane Blue, DORC, Zuidland The Netherlands). The PPV calibers used were 23G and 25G.We included 20 eyes from 20 patients who had developed ERM after lensectomy with implantation of a Physiol MicroF® IOL. In all 20 cases, we recorded a posterior vitreous detachment before the PPV. There was no case with pseudohole-type ERM. The ERM stage in all cases was $1 \mathrm{~B}$ or $1 \mathrm{C}$ of group 1 according to the classification proposed by Hwang and Sohn in 2012 [16]. The patients underwent PPV with ERM between January 2015 and September 2018. Minimum follow-up was 12 months. Exclusion criteria were intra- or postoperative complications, glaucoma, retinal detachment, recent retinal vascular occlusion syndromes, or any optic nerve impairments before or after lensectomy.

The main outcome measure was the change in mean visual acuity produced by ERM and after PPV in pseudophakic eyes with a trifocal IOL. The secondary outcome measures were change in mean CMT, recovery of the ellipsoid zone after PPV in the SD-OCT which was defined by an image of a continuous hyperreflective line corresponding to the IS/OS junction, which was judged as an intact IS/OS junction (total recovery); when the image showed cysts in the outer layer and a discontinuous IS/OS junction, it was therefore labeled as a disrupted IS/OS junction (no/partial recovery) as defined by Inoue and Morita in 2011 [6]. Other secondary outcomes was CDVA prior to PPV, with measures assessed by comparing 2 groups (one with $\geq 0.2 \log M A R$ and the other with $<0.2 \log M A R$ ), and the shift in spherical equivalent (SE).

\section{Statistical Analysis}

Time series were analyzed using traditional ANOVA, when all assumptions were met, or robust ANOVA, when some of the assumptions were violated. Independent samples were compared using the $t$ test or the Yuen-Welch test depending on the distribution of the variables. Finally we applied regression methods to measure correlation between numeric variables [17]. All calculations were performed with $\mathrm{R}$ version 3.5.3 of 2019 (R Foundation for Statistical Computing, Vienna, Austria).

\section{Results}

We recorded data on 20 eyes from 20 patients (12 males [60\%] and 8 females [40\%], 13 right eyes [65\%] and 7 left eyes [35\%]), with a mean age of $63 \pm 3$ years (range, 54 to 77 years). The mean time between lensectomy and PPV was $607 \pm 274$ days (range 92 to 1680 days). Follow-up was longer than 12 months after the PPV in all cases with a mean of $447 \pm 394$ days (range 341 to 911 days). All demographic data are listed in Table 1. No complications were recorded during the PPV procedures, and no visualization difficulties were reported by any of the retina surgeons. 


\begin{tabular}{|c|c|}
\hline Patients & 20 \\
\hline Age (Min to Max; Mean ( \pm SD)) & 54 to $77 ; 63$ \\
\hline & $( \pm 3)$ \\
\hline \multicolumn{2}{|l|}{ Sex, No. (\%) } \\
\hline Male & $12(60 \%)$ \\
\hline Female & $8(40 \%)$ \\
\hline \multicolumn{2}{|l|}{ Eye, No. (\%) } \\
\hline RE & $13(65 \%)$ \\
\hline LE & $7(35 \%)$ \\
\hline \multicolumn{2}{|l|}{ Stain, No. (\%) } \\
\hline TRYPAN BLUE & $2(10 \%)$ \\
\hline BRILLIANT BLUE & $1(5 \%)$ \\
\hline DUAL BLUE & $17(85 \%)$ \\
\hline \multicolumn{2}{|l|}{ Calier, No. (\%) } \\
\hline $23 g$ & $19(95 \%)$ \\
\hline $25 \mathrm{~g}$ & $1(5 \%)$ \\
\hline \multicolumn{2}{|l|}{ Bioptics, No. (\%) } \\
\hline No & $18(90 \%)$ \\
\hline Yes & $2(10 \%)$ \\
\hline \multicolumn{2}{|l|}{ YAG, No. (\%) } \\
\hline No & $19(95 \%)$ \\
\hline Yes & $1(5 \%)$ \\
\hline
\end{tabular}




\section{Note.}

\section{Stain = type of stain used for epiretinal membrane peeling; YAG = Neodymium- YAG capsulotomy.}

\section{Visual Acuity Results}

Three months after lensectomy, the mean UDVA Snellen was $0.08 \pm 0.03 \log M A R$, which decreased to $0.35 \pm 0.13 \log M A R$ at diagnosis of ERM, and $0.19 \pm 0.09 \log M A R$ at 12 months after surgery (Fig. 1). CDVA was $0.03 \pm 0.03 \log M A R$ after lensectomy and $0.23 \pm 0.10 \log M A R$ at diagnosis of ERM, improving to $0.10 \pm 0.04 \log M A R 6$ months after PPV (Fig. 2), with no values greater than 0.39 logMAR. These changes were statistically significant (Table 2). The mean UNVA 3 months after multifocal lensectomy was Jaeger $2.62 \pm 0.51$. UNVA was worse before PPV Jaeger $5.46 \pm 1.67$, although it improved to Jaeger $2.69 \pm 0.84$ at 12 months after PPV (Table 2). These changes were statistically significant (Fig. 3). The mean UNVA 12 months after PPV was Jaeger $2.56 \pm 0.51$ in eyes with complete recovery of the ellipsoid zone, compared with eyes with partial or no recovery, in which it was Jaeger $4.29 \pm 1.01(p=0.009)$. A comparison of visual results in 2 groups of CDVA before PPV, one with $\log M A R<0.2$ and the other with $\log M A R \geq 0.2$ revealed statistically significant differences $(p=0.024)$ (Fig. 4$)$.

Table 2

Visual Results

\begin{tabular}{|lcllll}
\hline Variable & N & After IOL & ERM & After PPV & pValue \\
\hline $\begin{array}{l}\text { Spherical } \\
\text { equivalent (D) }\end{array}$ & 20 & $\begin{array}{l}-0.18( \pm \\
0.38)\end{array}$ & $0.02( \pm 0.40)$ & $-0.18( \pm 0.47)$ & $0.140^{\star}$ \\
CDVA (LogMar) & 20 & $\begin{array}{l}0.03( \pm \\
0.03)\end{array}$ & $0.23( \pm 0.10)$ & $0.10( \pm 0.04)$ & $<$ \\
UDVA (LogMar) & 20 & $\begin{array}{l}0.08( \pm \\
0.03)\end{array}$ & $0.35( \pm 0.13)$ & $0.19( \pm 0.09)$ & $<$ \\
& & & & $0.001 \dagger$ \\
UNVA (Jaeger) & 20 & $\begin{array}{l}2.62( \pm \\
0.51)\end{array}$ & $5.46( \pm 1.67)$ & $2.69( \pm 0.84)$ & $<$ \\
OCT & 20 & NA & $380.15( \pm$ & $\begin{array}{l}313.70( \pm \\
36.98)\end{array}$ & $<$ \\
& & & $60.50)$ & $0.0011^{\star}$
\end{tabular}

Note: $\mathrm{N}=$ sample; $\mathrm{IOL}$ = intraocular lens; $\mathrm{ERM}=$ epiretinal membrane; $\mathrm{PPV}=$ pars plana vitrectomy; CDVA = corrected distance visual acuity; UDVA = uncorrected distance visual acuity results in logMAR; UNVA = uncorrected near visual acuity results in Jaeger; CMT = central macular thickness in $\mu \mathrm{m}$.

* Repeated measures ANOVA

† Robust repeated measures ANOVA due to outliers 


\section{Secondary Outcomes}

Mean CMT at diagnosis of ERM was $380.15 \pm 60.50 \mu \mathrm{m}$ (range, 312 to $501 \mu \mathrm{m}$ ). Six months after PPV, the mean CMT had fallen to $313.70 \pm 36.98 \mu \mathrm{m}$ (range, 274 to $419 \mu \mathrm{m}$ ), and although the difference was statistically significant ( $p=0.00083, t$ test) (Table 2$)$, there was no strong correlation after application of the Pearson and ordinary least squares methods (Fig. 5). We observed a correlation between mean CDVA 12 months after vitrectomy and recovery of the ellipsoid zone, which was $0.07 \pm 0.03 \log M A R$ in patients in whom recovery was complete, and $0.14 \pm 0.06 \log M A R$ in those with an incomplete recovery $(p=0.022)$ (Table 3).

Table 3

Visual Results Comparing Recovery of the External Retinal Layers (ERL)

Results for mean corrected distance visual acuity (logMAR) after pars plana vitrectomy after
comparing restoration of the external retinal layers.

\begin{tabular}{|llll|}
\hline IS-OS recovery & $\mathbf{N}$ & Mean $( \pm)$ & Range (Min/Max) \\
\hline Yes & 11 & $0.07( \pm 0.03)$ & $0.00 / 0.15$ \\
\hline No & 9 & $0.14( \pm 0.06)$ & $0.08 / 0.40$
\end{tabular}

Note: $\mathrm{N}$ = sample; IS-OS = ellipsoid zone; yes = complete recovery of external retinal layers (ERL); no = incomplete recovery of ERL.

Due to outliers trimmed means are shown. Yuen test for trimmed means, $p=0.022$

The stains used were Membrane Blue Dual in 17 eyes (85\%) and Brilliant Blue in 2 eyes (10\%) and Trypan Blue in 1 eye (5\%). As for PPV calibers we recorded 23G in 19 eyes (95\%) and 25G in 1 eye (5\%). No recurrence of ERM was observed during follow-up. We did not observe any correlation between CDVA after PPV and the time lapse between lensectomy and PPV $(p=0.92)$. The correlation between the CDVA and the stain or the caliber of PPV used for the removal of ERM could not be established owing to insufficient number of cases.

A bioptics procedure by photorefractive keratectomy was performed 3 months after lensectomy in 2 eyes $(10 \%)$ and no refractive adjustment was made after vitrectomy. Nd-YAG laser capsulotomy was necessary in 1 eye (5\%) 24 months after lensectomy and 6 months before PPV. No cases of tilting or decentration of the lens were observed, during or after the PPV.

The only complication we recorded after PPV (5\%) was a case of cystoid macular edema in a diabetic patient with no signs of diabetic retinopathy who responded well to topical nonsteroidal antiinflammatory drugs and corticosteroids (final CDVA, 0.07 logMAR). 
Comparison of the SE 3 months after lensectomy with the SE at diagnosis of ERM showed that the mean value had changed from $-0.18 \pm 0.38 D$ to $0.02 \pm 0.40 \mathrm{D}$; this difference was not significant $(p=0.14)$. When the mean SE after lensectomy is compared with the SE 12 months after PPV, which was $-0.18 \pm$ $0.21 \mathrm{D}$, the difference continued to be nonsignificant $(p=0.98)$ (Table 2) (Fig. 6). We also compared the mean change in SE after lensectomy with the SE at the last visit 12 months after PPV in 2 groups, one with sutured sclerotomies and the other without sutured sclerotomies, and we did not observed a statistically significant difference between them $(p=0.256)$.

\section{Discussion}

The results of this retrospective study are similar in terms of mean gain in CDVA to those recorded in patients with monofocal IOL implants [18-21], thus mitigating one of the main concerns with respect to implantation of multifocal IOLs which is the rationale of this study and is consistent with the outcomes observed for multifocal IOL implants in eyes with other macular diseases, such as aged-related macular degeneration and diabetic retinopathy [12]. Our observation seems to be more associated with macular SD-OCT findings in the ellipsoid zone (IS/OS junction) recovery, as observed and discussed by Inoue and Morita $[6,22]$.The mean UNVA results also improved significantly after the decrease recorded at diagnosis of ERM, which is also associated in our study with complete recovery of the ellipsoid zone. The decrease observed was based on comparison with eyes for which no recovery was recorded or recovery was only partial, although an acceptable UNVA was maintained in some of these eyes.

None of the surgeons reported any perioperative difficulty related to the design of the diffractive rings or lens, despite the data published by Yoshino and Inoue in 2010 [23], who reported visualization difficulties during PPV for ERM. However, it is important to note that the IOL model in that case was different (ZM900 ®; Abbott Medical Optics, Johnson and Johnson Vision, Santa Ana, California, USA).

Consistent with reports from other authors [18-21], the best mean CDVA results were obtained in eyes with better visual acuity before vitrectomy, with a p value of 0.024 between patients with a CDVA logMAR $<0.2$ and those with a CDVA $\log M A R \geq 0.2$. This finding supports the indication of this procedure for symptomatic eyes diagnosed with ERM and good CDVA.

We did not observe any case of retinal detachment even though this complication has been reported after 1 year of follow-up in a large series of eyes with monofocal lenses (362 eyes) undergoing PPV for ERM $(2.5 \%)$ by Guillaubey and Malvitte [24]. Inclusion of more cases in our study may have revealed cases of retinal detachment.

No significant myopic shift was observed in our study when SE after lensectomy was compared with SE after PPV, even when comparing eyes with or without sutured sclerotomies, thus explaining why no refractive adjustment after vitrectomy was required. In a similar study of 28 pseudophakic eyes with a monofocal IOL, Hamoudi and Kofod in 2013 observed a clearly significant myopic shift after PPV, although the follow-up period was 8.5 months [25]. In another review article, Hamoudi and La Cour reported different shifts in SE, even though other conditions and techniques were included [26]. 
In their pilot study, Patel et al. implanted a bifocal IOL (AcrySof IQ ReSTOR® SN6AD1; Alcon Laboratories, Inc., Fort Worth, TX, USA) during phacoemulsification combined with PPV in 6 eyes with cataract and ERM. The authors reported good visual and anatomical outcomes after only 3 months, despite using indocyanine green to stain [27]. Even though visual results with this trifocal IOL model are good, we do not consider its implantation when performing a combined procedure of phacoemulsification and PPV for ERM that could potentially work but involves a high risk of intolerance and may require explantation of the IOL. A safer option could be to perform the PPV for ERM and later on the phacoemulsification with a trifocal IOL implantation, once the macular recovery is complete.

Although this study is based on 20 eyes, to our knowledge, is the largest of this increasingly common indication to date, with a single trifocal IOL model. Despite this sample size is small, the data can endorse the purpose of this study, but further studies with bigger samples are needed to support it widely. One strength of the study is the long follow-up period (>12 months) for all of the eyes included. Our study is limited by its retrospective design, the use of 3 different SD-OCT devices (because of potential interference with the CMT results), and the fact that surgery and follow-up involved more than 1 surgeon.

\section{Conclusions}

This model of diffractive trifocal IOLs does not seem to affect the outcome of PPV for ERM peeling, with good visual results not only for distance, but also for near visual acuity. Other more relevant factors seem to be involved. Larger-scale and prospective studies are needed to confirm our observations.

\section{Declarations}

Conflict of Interest: None of the authors has a conflict of interest to report and received no support for the study.

Data Availability: All the data used to support the findings of this study are available from the corresponding author upon reasonable request.

Ethical approval: this research was approved by the Institutional Review Board and the Research and Development Department before recruitment was initiated and followed the stipulations of the declaration of Helsinki.

Consent to participate: Informed consent was obtained from all individual participants included in the study.

Consent for publication: all the patients signed informed consent regarding publishing their data.

\section{Acknowledgements}

The authors are grateful to Thomas O’Boyle for writing assistance. 


\section{Corresponding author:}

Luis Arrevola-Velasco

Clínica Baviera

Paseo de la Castellana, 20

28046 Madrid Spain

T: +(34) 610222760

F: +(34) 917820360

e-mail: larrevola@telefonica.net

ORCID: 0000-0003-3828-8524

\section{References}

1. Bu SC, Kuijer R, Li XR, Hooymans JM, Los LI. Idiopathic epiretinal membrane (Review). Retina. 2014; 34: 2317-2335. https://doi.org/10.1097/IAE.0000000000000349.

2. Fraser-Bell S, Guzowski M, Rochtchina $E$, et al. Five-year cumulative incidence and progression of epiretinal membranes: the Blue Mountains Eye Study. Ophthalmology. 2003; 110: 34-40. http://doi.org/10.1016/s0161-6420(02)01443-4.

3. $\mathrm{Ng} \mathrm{CH}$, Cheung N, Wang JJ, et al. Prevalence and risk factors for epiretinal membranes in a multiethnic United States population. Ophthalmology. 2011; 118: 694-699. http://doi.org/10.1016/j.ophtha.2010.08.009.

4. Machemer R. The surgical removal of epiretinal macular membranes (macular puckers). Klin Monbl Augenheilkd. 1978; 173: 36-42. PMID: 692034.

5. Kim M, Park IS, Lee DH, Koh HJ, Lee SC, Kim SS. Comparison of surgical outcome of 23-gauge and 25-gauge microincision vitrectomy surgery for management of idiopathic epiretinal membrane in pseudophakic eyes. Retina. 2015;35: 2115-2120. http://doi.org/10.1097//AE.0000000000000598.

6. InoueM, Morita S, Watanabe Y, Kaneko T, Yamane S, Kobayashi S, et al. Preoperative Inner segment/outer segment in spectral domain optical coherence tomography as a prognostic factor in epiretinal membrane surgery. Retina. 2011; 31:1366-1372. http://doi.org/10.1097/IAE.0b013e318203c156.

7. Joe SG, Lee KS, Lee JY, Hwang JU, Kim JG, Yoon YH. Inner retinal layer thickness is the major determinant of visual acuity in patients with idiopathic epiretinal membrane.ActaOphthalmol.2013;91:e242-243. http://doi.org/10.1111/aos.12017.

8. Eurostat: Surgical operations and procedures performed in hospitals by ICD-9-CM Available at: https://ec.europa.eu/eurostat/statistics 
explained/index.php/Surgical_operations_and_procedures_statistics\#lnpatient_procedures:_cataract_surgery. Last accessed July 10, 2020.

9. De VriesNE, Nuijts RM. Multifocal intraocular lenses in cataract surgery: Literature review of benefits and side effects. J Cataract Refract Surg. 2013; 39:268-278.

http://doi.org/10.1016/j.jcrs.2012.12.002.

10. Plaza-Puche AB, Alio JL, Sala E, Mojzis P.Impact of low mesopic contrast sensitivity outcomes in different types of modern multifocal intraocular lenses. Eur J Ophthalmol. 2016; 4 ;26: 612-617. http://doi.org/10.5301/ejo.5000777.

11. Alio J, Plaza-Puche AB, Férnandez-Buenaga R, Pikkel J, Maldonado M, Multifocal Intraocular Lenses: An Overview. Survey of Ophthalmology. 2017; 62:611-634.

http://doi.org/10.1016/j.survophthal.2017.03.005.

12. Grzybowski A, Kanclerz P, Tuuminen R. Multifocal intraocular lenses and retinal diseases. Graefes Arch Clin Exp Ophthalmol. 2020; 258:805-813. http://doi.org/10.1007/s00417-020-04603-0.

13. YangY, Yan YN, Wang YX, Xu J, Ren J, Xu L, et al. Ten-year cumulative incidence of epiretinal membranes assessed on fundus photographs. The Beijing Eye Study 2001/2011. PLoS One. 2018; 13:e0195768. http://doi.org/ 10.1371/journal.pone.0195768.

14. Fong, C. S., Mitchell, P., Rochtchina, E., Hong, T., de Loryn, T., \& Wang, J. J. Incidence and Progression of Epiretinal Membranes in Eyes After Cataract Surgery. Am J Ophthalmol. 2013; 156(2), 312318.http://doi.org/10.1016/j.ajo.2013.03.022.

15. Mitchell, P., Smith, W., Chey, T., Wang, J. J., \& Chang, A. Prevalence and Associations of Epiretinal Membranes. Ophthalmology. 1997; 104(6), 1033-1040.http://doi.org/10.1016/s01616420(97)30190-0.

16. Hwang J, Sohn J, Moon B G, Joe S G, Lee J Y, Kim JG, Yoon YH. Assessment of Macular Function for Idiopathic Epiretinal Membranes Classified by Spectral-Domain Optical Coherence Tomography. Invest Opthalmol Vis Sci. 2012;53(7):3562-9. http://doi.org/10.1167/iovs.12-9762.

17. Wilcox R. Introduction to Robust Estimation and Hypothesis Testing: Statistical Modeling and Decision Science. Academic press 2005.

18. Thompson JT. Epiretinal membrane removal in eyes with good visual acuities. Retina. 2005; 25:875882. http://doi.org/10.1097/00006982-200510000-00010.

19. Lehpamer BP, Carvounis PE. Pars Plana Vitrectomy for Symptomatic Epiretinal Membranes in Eyes with 20/50 or Better Preoperative Visual Acuity. Retina. 2015; 35:1822-1827. http://doi.org/ 10.1097/IAE.0000000000000541.

20. Reilly G, Melamud A, Lipscomb P, Toussaint B. Surgical Outcomes in Patients with Macular Pucker and Good Preoperative Visual Acuity after Vitrectomy with Membrane Peeling. Retina. 2015; 35:18171821. http://doi.org/10.1097//AE.0000000000000558.

21. Rahman R, Stephenson J. Early surgery for epiretinal membrane preserves more vision for patients. Eye (Lond). 2014; 28:410-414. http://doi.org/10.1038/eye.2013.305. 
22. Inoue M, Morita S, Watanabe Y, Kaneko T, Yamane S, Kobayashi S, et al. Inner segment/outer segment junction assessed by spectral domain optical coherence tomography in patients with idiopathic epiretinal membrane. Am J Ophthalmol. 2010; 150: 834-839. http://doi.org/10.1016/j.ajo.2010.06.006.

23. YoshinoM, Inoue M, Kitamura N, Bissen-Miyajima $\mathrm{H}$. Diffractive multifocal intraocular lens interferes with intraoperative view. Clin Ophthalmol. 2010; 4:467-469. http://doi.org/ 10.2147/opth.s8831

24. Guillaubey A, Malvitte L, Lafontaine PO, Hubert I, Bron A, Berrod JP. Incidence of retinal detachment after macular surgery: a retrospective study of 634 cases. Br J Ophthalmol. 2007; 91:1327-1330. http://doi.org/10.1136/bjo.2007.115162.

25. HamoudiH, Kofod M, La Cour M. Refractive changes after vitrectomy for epiretinal membrane in pseudophakic eyes. Acta Ophthalmol. 2013; 91:434-436. http://doi.org/ 10.1111/j.17553768.2012.02574.x.

26. Hamoudi H, La Cour M. Refractive changes after vitrectomy and phacovitrectomy for macular hole and epiretinal membrane. J Cataract Refract Surg. 2013; 39:942-947. http://doi.org/10.1016/j.jcrs.2013.04.012.

27. PatelSB, Snyder ME, Riemann CD, Foster RE, Sisk RA. Short-term outcomes of combined pars plana vitrectomy for epiretinal membrane and phacoemulsification surgery with multifocal intraocular lens implantation. Clin Ophthalmol. 2019; 13:723-730. http://doi.org/10.2147/OPTH.S195928.

\section{Figures}




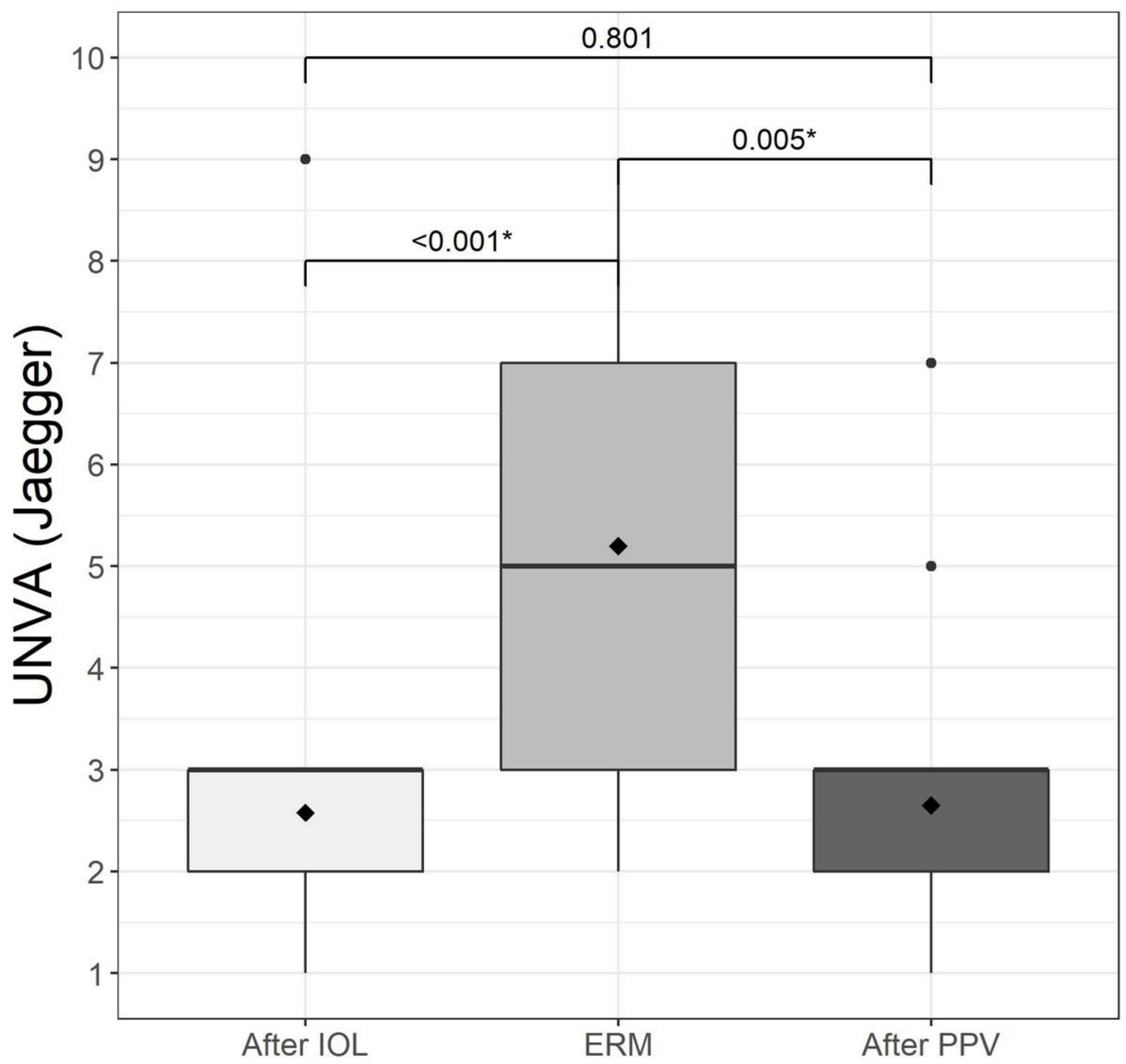

Figure 1

Mean uncorrected distance visual acuity (UDVA) in logMAR after implantation of the trifocal intraocular lens (IOL), when the epiretinal membrane (ERM) appeared, and after pars plana vitrectomy (PPV). 


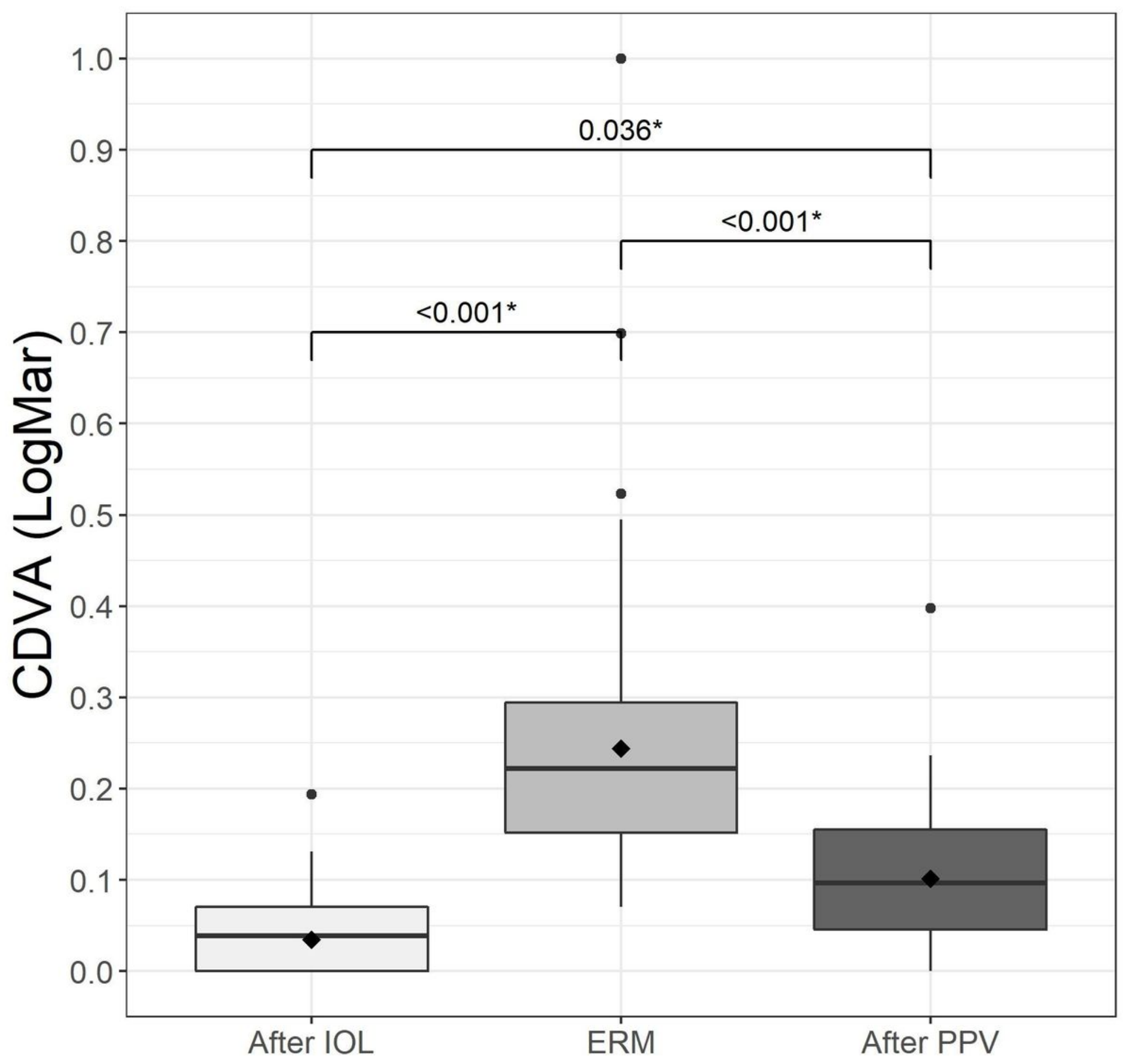

Figure 2

Mean corrected distance visual acuity (CDVA) in logMAR after implantation of the trifocal intraocular lens (IOL), when the epiretinal membrane (ERM) appeared, and after pars plana vitrectomy (PPV). 


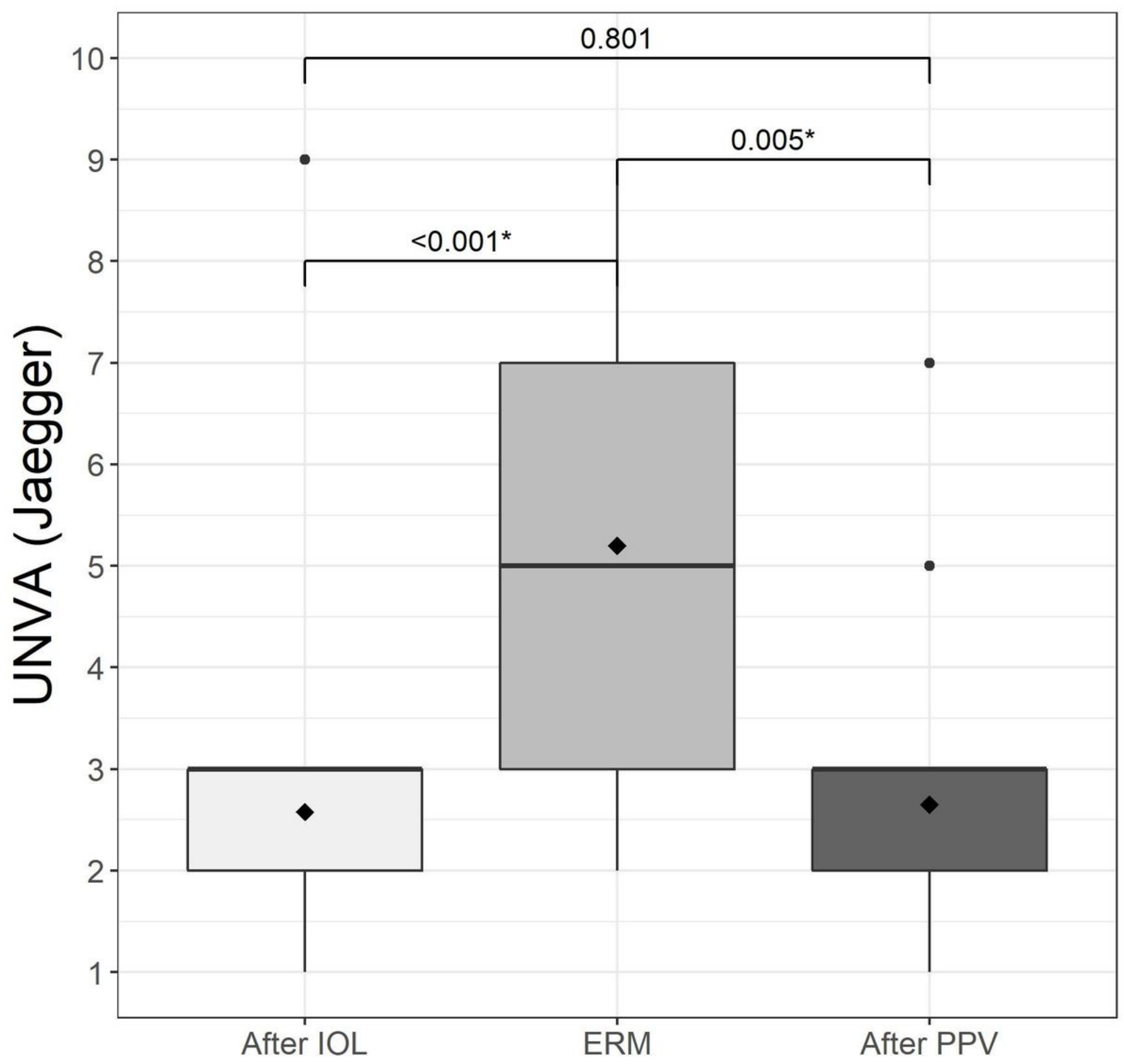

Figure 3

Mean uncorrected near visual acuity (UNVA) in logMAR after implantation of the trifocal intraocular lens (IOL), when the epiretinal membrane (ERM) appeared, and after pars plana vitrectomy (PPV). 


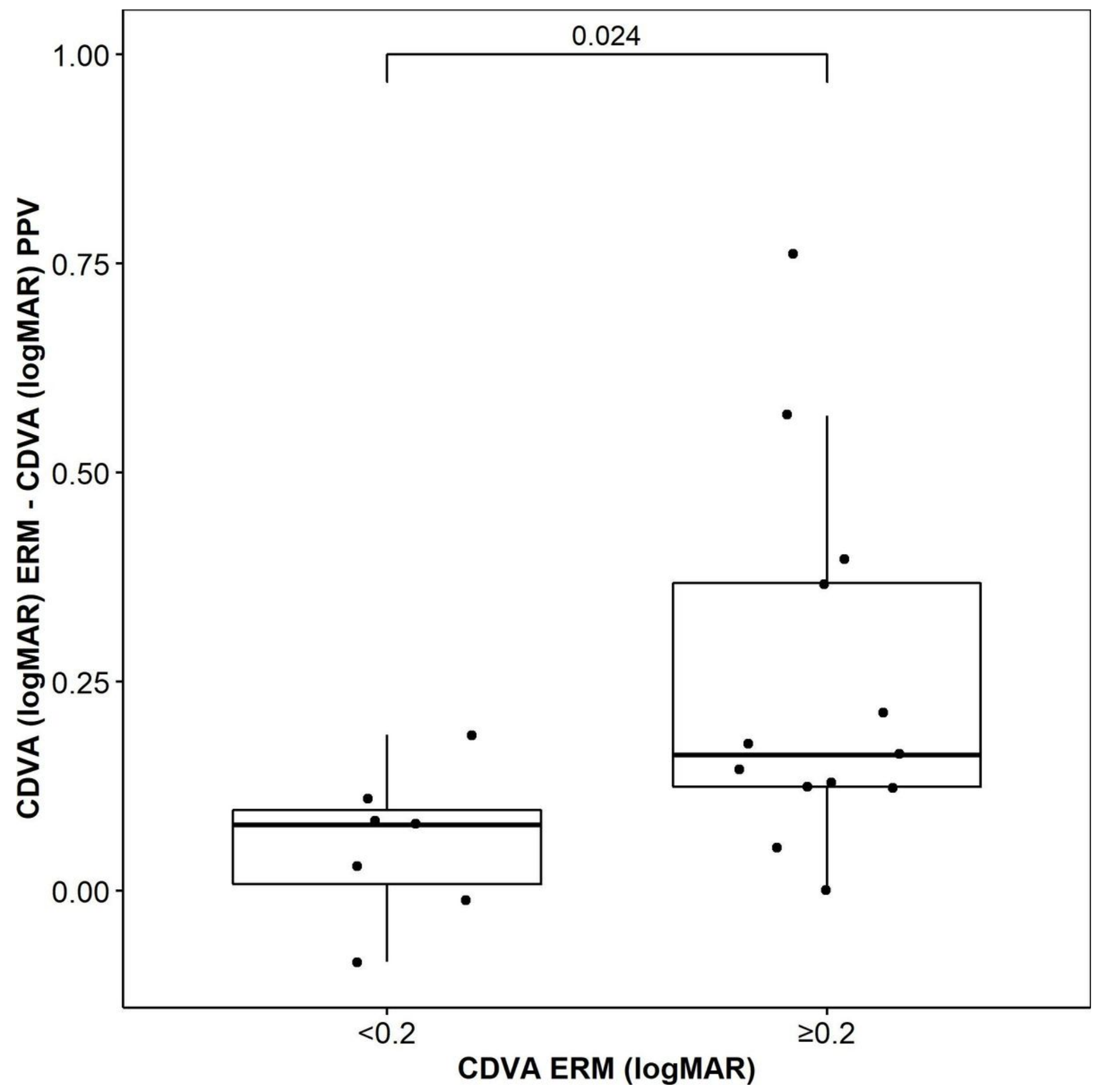

Figure 4

Corrected distance visual acuity (CDVA) in logMAR after pars plana vitrectomy (PPV) vs CDVA when the epiretinal membrane (ERM) appeared $(\geq 0.2 \log M A R$ or $<0.2 \log M A R)$. 


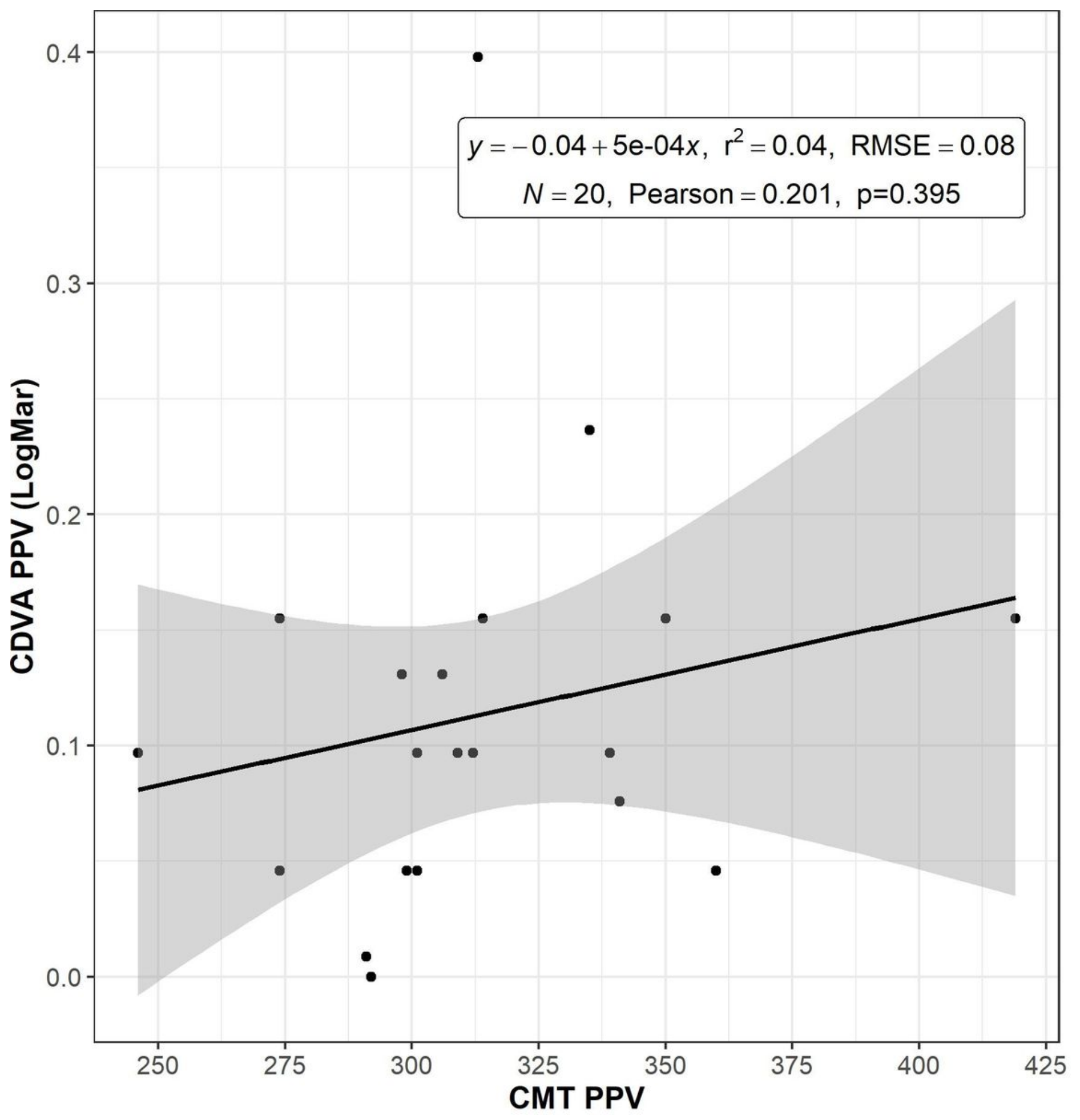

Figure 5

Correlation between mean corrected distance visual acuity (CDVA) in logMAR and mean central macular thickness (CMT) registered with spectral domain optical coherence tomography (OCT) in microns after pars plana vitrectomy (PPV). 


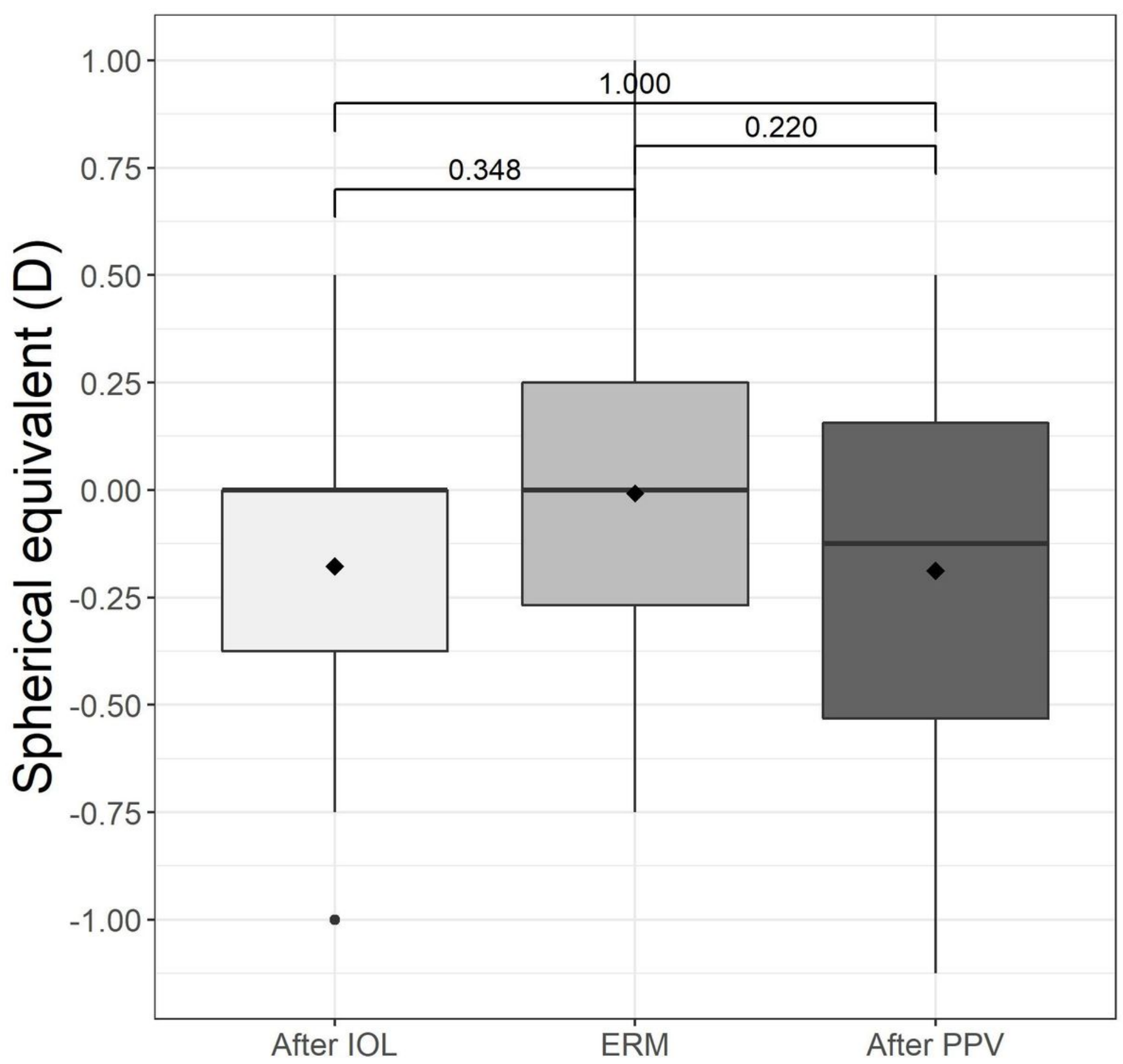

Figure 6

Spherical equivalent (SE) in diopters (D) after implantation of the trifocal intraocular lens (IOL), when the epiretinal membrane (ERM) appeared and after pars plana vitrectomy (PPV). 